\title{
Comparison of green pit viper and Agkistrodon halys antivenom in inhibition of coagulopathy due to Trimeresurus albolabris venom: an in-vitro study using human plasma
}

\author{
SK Lam *, SF Yip, Paul Crow, HT Fung, Jeff MH Cheng, KS Tan, OF Wong, Daisy YT Yeung, YK Wong, \\ KM Poon, Gary Ades
}

\section{A B S T R A C T}

Introduction: There are two antivenoms that may be administered in Hong Kong following a bite by Trimeresurus albolabris: the green pit viper antivenom from the Thai Red Cross Society in Thailand and the Agkistrodon halys antivenom from the Shanghai Institute of Biological Products in China. Both are recommended by the Central Coordinating Committee of Accident and Emergency Services of the Hospital Authority for treating patients with a bite by Trimeresurus albolabris. The choice of which antivenom to use is based on physician preference. This study aimed to compare the relative efficacy of the two antivenoms.

Methods: This in-vitro experimental study was carried out by a wildlife conservation organisation and a regional hospital in Hong Kong. Human plasma from 40 adult health care worker volunteers was collected. The Trimeresurus albolabris venom was added to human plasma and the mixture was assayed after incubation with each antivenom (green pit viper and Agkistrodon halys) using saline as a control. Fibrinogen level and clotting time in both antivenom groups were studied.

Results: The mean fibrinogen level was elevated from $0 \mathrm{~g} / \mathrm{L}$ to $2.86 \mathrm{~g} / \mathrm{L}$ and $1.11 \mathrm{~g} / \mathrm{L}$ after the addition of green pit viper antivenom and Agkistrodon halys antivenom, respectively. When mean clotting time was measured, the value was 6.70 minutes in the control, prolonged to more than 360 minutes by green pit viper antivenom and to 19.06 minutes by Agkistrodon halys antivenom.

Conclusions: Green pit viper antivenom was superior to Agkistrodon halys antivenom in neutralisation of the thrombin-like and hypofibrinogenaemic activities of Trimeresurus albolabris venom.

\section{Hong Kong Med J 2017;23:13-8 \\ DOI: $10.12809 / \mathrm{hkmj} 154617$}

${ }^{1}$ SK Lam *, FHKAM (Emergency Medicine)

${ }^{2}$ SF Yip, FHKAM (Pathology), FHKAM (Medicine)

${ }^{3}$ P Crow, BSc (Zoology)

${ }^{1}$ HT Fung, FHKAM (Emergency Medicine)

JMH Cheng, MSc (Biomedical Science)

${ }^{3} \mathrm{KS}$ Tan, BSc

${ }^{5}$ OF Wong, FHKAM (Emergency Medicine), FHKAM (Anaesthesiology)

${ }^{4}$ DYT Yeung, BSc (Biomedical Science)

${ }^{3}$ YK Wong, BSc

${ }^{1}$ KM Poon, FHKAM (Emergency Medicine)

${ }^{3} \mathrm{G}$ Ades, $\mathrm{PhD}$

1 Department of Accident and Emergency, Tuen Mun Hospital, Tuen Mun, Hong Kong

${ }^{2}$ Department of Pathology and Department of Medicine and Geriatrics, Tuen Mun Hospital, Tuen Mun, Hong Kong

${ }^{3}$ Fauna Conservation Department, Kadoorie Farm and Botanic Garden, Tai Po, Hong Kong

${ }^{4}$ Department of Pathology, Tuen Mun Hospital, Tuen Mun, Hong Kong

${ }^{5}$ Department of Accident and Emergency, North Lantau Hospital, Lantau, Hong Kong

* Corresponding author: tommylam@yahoo.com

- In human plasma, both green pit viper antivenom (GPVA) and Agkistrodon halys antivenom (AHA) can antagonise the haemotoxicity in terms of fibrinogen and clotting time derangement induced by Trimeresurus albolabris venom.

- In contrast to a lower protection against mortality in mice in a previous study, the species-specific GPVA is more potent than AHA on a volume basis in neutralisation of the haemotoxic effects in humans.

Implications for clinical practice or policy

- GPVA is preferable to AHA in reversing the haemotoxicity in T albolabris envenomation.

- Evaluation of other haemotoxicity parameters such as platelet count may give a more comprehensive understanding of the relative efficacy of the two antivenoms.

- A clinical trial in human snakebite victims should be conducted to validate the clinical applicability of our study results and provide information about appropriate antivenom dosage. 


\section{比較竹葉青蛇和蝮蛇的抗毒血清在抑制白唇竹葉 青蛇毒的凝血作用：使用人類血漿的體外研究 \\ 林成傑、葉仕輝、Paul Crow、馮顯達、鄭文浩、陳結山、 \\ 黃凱峯、楊雨鈿、黃宇祺、潘健明、艾加里}

引言：在香港, 被白唇竹葉青蛇咬傷可使用兩種抗蛇毒血清 : 泰國紅 十字會的竹葉青蛇抗毒血清, 以及上海生物製品研究所的蝮蛇抗毒血 清。兩者均由醫院管理局急症室服務的中央協調委員會推薦使用, 醫 治被白唇竹葉青蛇咬傷的患者。至於使用哪種抗蛇毒血清則視乎主診 醫生的判斷。本研究旨在比較兩種抗蛇毒血清的相對效用。

方法：這項體外實驗研究是由香港一個野生動物保護組織和一所分區 醫院合作進行。研究共收集40名志願醫療成年工作者的血墏, 把白唇 竹葉青蛇的毒液加入血漿中, 並將該混合物與分別來自竹葉青蛇和蝮 蛇的抗蛇毒血清作細胞培養測定, 並以鹽水作為對照, 繼而量度兩組 抗蛇毒血清的纖維蛋白原水平和凝血時間。

結果: 加入竹葉青蛇和蝮蛇的抗蛇毒血清後, 平均纖維蛋白原水平由 原來的 $0 \mathrm{~g} / \mathrm{L}$ 分別升至 $2.86 \mathrm{~g} / \mathrm{L}$ 和 $1.11 \mathrm{~g} / \mathrm{L}$ 。以鹽水作對照的平均凝血時 間為6.70分鐘, 使用竹葉青蛇的抗蛇毒血清延長至超過 360 分鐘, 蝮 蛇的抗蛇毒血清則延至 19.06 分鐘。

結論：竹葉青蛇的抗蛇毒血清在中和白唇竹葉青蛇的凝血酶類和低纖 維蛋白原血症方面勝過蝮蛇的抗蛇毒血清。

\section{Introduction}

Snakebite is an important medical emergency in Hong Kong. The consequences are potentially serious, especially if not treated quickly and appropriately. In 2014, 121 cases were recorded by the Clinical Data Analysis and Reporting System of the Hospital Authority in Hong Kong. Trimeresurus albolabris, also known locally as the white-lipped pit viper or bamboo snake, accounts for $95 \%$ of all human envenomation cases. ${ }^{1}$ Its bite can cause potentially life-threatening bleeding. ${ }^{2}$ In Hong Kong, death following a $T$ albolabris is, fortunately, rare. The last reported case occurred in 1986 when an aged woman died of cerebral haemorrhage. ${ }^{3}$ Nonetheless non-lethal coagulopathy is common. In a local case series $(n=21)$, laboratory coagulation abnormalities were frequent (hypofibrinogenaemia in $48 \%$ of cases, prolonged prothrombin time [PT] in $19 \%$, and prolonged activated partial thromboplastin time [aPTT] in 14\%) and sometimes accompanied by bleeding (skin bruising in one patient, both gastrointestinal haemorrhage and haematuria in another). ${ }^{4}$

Trimeresurus albolabris venom has a thrombinlike effect in vitro but causes a defibrination syndrome in vivo. The snake venom's thrombin-like enzymes are responsible for the formation of friable and loose fibrin clots, hypofibrinogenaemia, and defibrination syndrome. ${ }^{5}$ We studied the thrombin- like effect and defibrinating activity of $T$ albolabris venom by assessing the clotting time and fibrinogen level, respectively, in human plasma.

There are two antivenoms available in Hong Kong for $T$ albolabris bite, the green pit viper antivenom (GPVA; raised against $T$ albolabris) from the Thai Red Cross Society in Thailand and the Agkistrodon halys antivenom (AHA; raised against $A$ halys) from the Shanghai Institute of Biological Products in China. Both are recommended by the Central Coordinating Committee of Accident and Emergency Services of the Hospital Authority in treating patients with $T$ albolabris bite. ${ }^{6}$ Reports on their relative efficacy in reversing coagulopathy in humans are scarce. A case report described prompt reversal of coagulopathy that was refractory to two ampoules of AHA given 3 days apart by five vials of GPVA. ${ }^{7}$ Conclusions can hardly be drawn in this case, however, about whether the failure of AHA was due to the species mismatch or simply inadequate dosage. The choice of antivenom to use in a clinical setting is determined by physician preference. ${ }^{8}$ In this study, we compared the potency of GPVA and AHA against the haemotoxicity from $T$ albolabris envenoming using an in-vitro human plasma model.

\section{Methods}

This study was approved by the ethics committees of the New Territories West Cluster of Hospital Authority and Kadoorie Farm and Botanic Garden (KFBG), a non-governmental organisation actively participating in the conservation of Hong Kong wildlife.

\section{Venom}

From August to November 2013, herpetologists from KFBG identified $T$ albolabris for venom extraction from locally captured stray snakes. Venom was extracted by allowing the snakes to bite into a paraffin sheet over a plastic collection pot (Fig 1). The venom was extracted and stored in sterilised bottles at $-70^{\circ} \mathrm{C}$.

\section{Antivenom}

The GPVA (batch number TA00512) and AHA (batch number 20130401) [Fig 2] were purchased from the Thai Red Cross Society in Thailand and the Shanghai Institute of Biological Products in China, respectively. Both were $F\left(a b^{\prime}\right) 2$, in powder form, and reconstituted in $10 \mathrm{~mL}$ of sterile water in another vial in the same package before clinical use.

\section{Plasma preparation}

Blood was collected from 40 adult health care workers who had no history of snake bite. They had no history of any coagulopathy problems and were not prescribed any anticoagulant. The samples were 


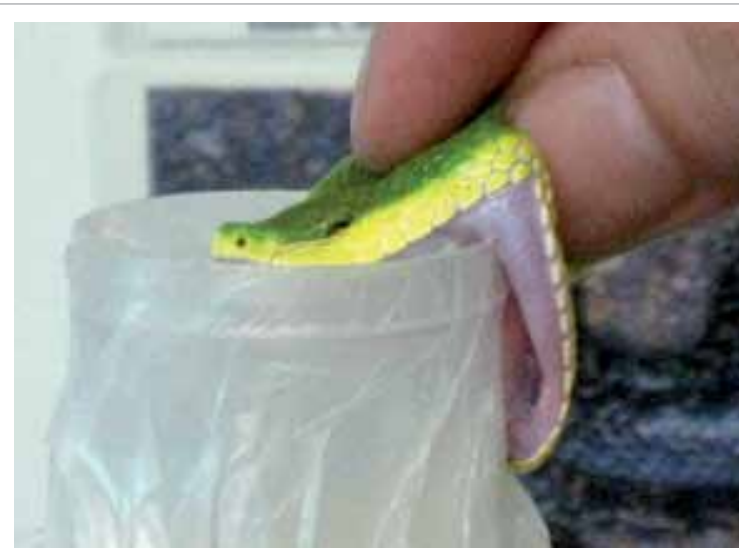

FIG I. Milking a Trimeresurus albolabris for venom collection

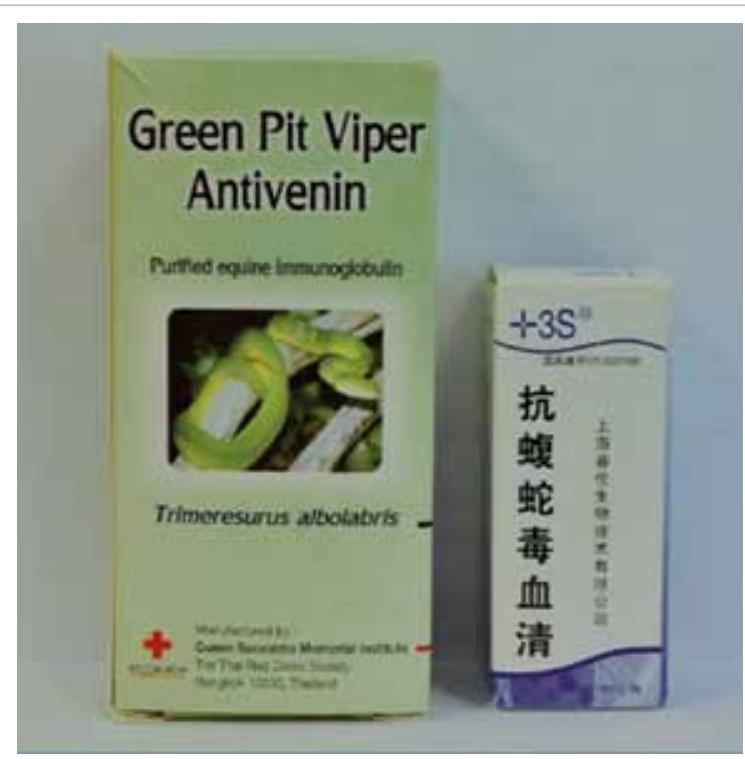

FIG 2. The green pit viper antivenom (left) from the Thai Red Cross Society in Thailand and the Agkistrodon halys antivenom (right) from the Shanghai Institute of Biological Products in China therefore be 1:100. The amount of venom yield per bite was 8 to $15 \mathrm{mg}$ for the $T$ albolabris. ${ }^{10}$ Venom yields are an average range for a 'standard' snake of the species and the amount of venom injected during a bite. ${ }^{10}$ If a maximum of $15 \mathrm{mg}$ of venom was injected into the circulation of an adult, the maximum concentration of venom in the circulating plasma would be around $5 \mu \mathrm{g} / \mathrm{mL}$ (lower in real snakebites unless intravascular inoculation occurs).

To simulate the in-vivo condition, plasma was incubated with venom at a concentration of $5 \mu \mathrm{g} / \mathrm{mL}$; the antivenom-to-plasma ratio used was 1:100, that is, $10 \mu \mathrm{L}$ of GPVA or AHA to $1000 \mu \mathrm{L}$ plasma.

This test was performed in duplicate and the mean result was analysed. Venom was added at a concentration of $50 \mu \mathrm{g} / \mathrm{mL}$ to homemade phosphate buffered saline. Then $100 \mu \mathrm{L}$ (5 $\mu \mathrm{g}$ venom) of this solution was added to $1000 \mu \mathrm{L}$ of human plasma in plain glass test tubes and mixed for 30 seconds. The final concentration of the testing mixtures was $5 \mu \mathrm{g}$ venom per $\mathrm{mL}$ plasma. Then $10 \mu \mathrm{L}$ of GPVA or AHA was mixed with the venom/plasma mixture and incubated at $37^{\circ} \mathrm{C}$ for 45 minutes. The same procedures were performed in controls using $10 \mu \mathrm{L}$ of saline instead of antivenom. The fibrinogen level was measured after 45 minutes using a Sysmex CA-7000 analyser (Siemens, Germany) with Thrombin Reagent (Clauss assay, Dade; Siemens, Germany).

\section{Clotting time assay}

The working venom was added at a concentration of $50 \mu \mathrm{g} / \mathrm{mL}$ to homemade phosphate buffered saline. An amount of $100 \mu \mathrm{L}$ antivenom (GPVA or AHA) was added to $1000 \mu \mathrm{L}$ of working venom solution. The samples were mixed and incubated at $37^{\circ} \mathrm{C}$ for 45 minutes. After incubation, one tenth or $110 \mu \mathrm{L}$ of the antivenom/venom mixture was withdrawn and added to $1000-\mu \mathrm{L}$ plasma. A final concentration of $5-\mu \mathrm{g}$ venom per $\mathrm{mL}$ plasma mixture was added to a glass test tube and clotting time was measured. The same procedures were performed in controls with $100 \mu \mathrm{L}$ of saline used instead of antivenom. Fibrin formation (precipitation) was carefully observed and clotting time was recorded. No fibrin clot observed after 360 minutes was recorded as no clot formation (NCF). Theoretically, NCF would indicate that all the clotting activity (thrombin-like effect) of the venom in the plasma had been completely neutralised by the neutralising antibodies in the antivenom.

\section{Data analysis and statistics}

Continuous variables such as fibrinogen level and clotting time were expressed as means and standard deviations. Analysis of variance (ANOVA) test and post-hoc Tukey's honest significant difference (HSD) test were used to compare three means. All statistical analysis was performed with the Statistical Package 
for the Social Sciences (Windows version 22.0; SPSS Inc, Chicago [IL], US).

\section{Results}

Venom was harvested from a total of 46 snakes and pooled together for subsequent testing. There were two bottles containing no venom, that is, dry bite. The total weight and total volume of venom collected was $2.3791 \mathrm{~g}$ and $2170 \mu \mathrm{L}$, respectively.

\section{Fibrinogen assay}

As illustrated in Table 1, GPVA showed a higher neutralising capacity against venom than AHA. The measured fibrinogen in the GPVA group (mean \pm standard deviation, $2.86 \pm 0.52 \mathrm{~g} / \mathrm{L}$ ) was higher than that in the AHA group $(1.11 \pm 0.23$ $\mathrm{g} / \mathrm{L}$ ), and undetectable in the control group, ie 0 $\mathrm{g} / \mathrm{L}$. The ANOVA test yielded significant variation between them. Post-hoc Tukey's HSD test showed that differences in all pairwise comparisons were statistically significant (Table 2).

\section{Clotting time assay}

The ANOVA was performed for the clotting time of the three groups and yielded significant variation.
Post-hoc Tukey's HSD test showed that all pairwise comparisons were significantly different (Table 2). The mean clotting time in the AHA group was 19.06 minutes, which was significantly longer than the 6.70 minutes in the control group (Table 1). This indicated that venom in the plasma was partly neutralised by the neutralising antibodies in AHA.

The mean clotting time in the GPVA group was $>360$ minutes, which was significantly longer than that in the AHA group (Table 1). The fulfilment of NCF definition implied that venom in the plasma was completely neutralised by the neutralising antibodies in GPVA.

\section{Discussion}

Although both belong to the family Viperidae and subfamily Crotalinae, $T$ albolabris and $A$ (synonym Gloydius) halys differ with respect to genus, geographic range, venom composition, and envenoming features. The species $T$ albolabris is endemic to South-East Asia encompassing Thailand, Vietnam, and southern China, including Hong Kong. Its toxins encompass jerdonitin (a metalloproteinase), stejnobin (a fibrinogen clotting enzyme), ${ }^{11}$ and alboaggregins (the platelet agglutinants). ${ }^{12}$ They give rise to local swelling and

TABLE I. The effects of green pit viper antivenom (GPVA) and Agkistrodon halys antivenom (AHA) on fibrinogen and clotting time assays

\begin{tabular}{lccccc}
\hline & \multicolumn{3}{c}{ Mean \pm standard deviation } & F & P value \\
\cline { 2 - 5 } & GPVA & AHA & Control & & \\
\hline Fibrinogen level (g/L) & $2.86 \pm 0.52$ & $1.11 \pm 0.23$ & $0 \pm 0$ & 112.6 & $<0.0005$ \\
Clotting time (mins) & $>360$ & $19.06 \pm 1.49$ & $6.70 \pm 0.56$ & 1913860 & $<0.0005$ \\
\hline
\end{tabular}

TABLE 2. The association between different antivenoms and testing parameters using Tukey's honest significant difference test

\begin{tabular}{|c|c|c|c|c|c|c|}
\hline & Antivenom (I) & $\begin{array}{c}\text { Antivenom } \\
\text { (J) }\end{array}$ & $\begin{array}{c}\text { Mean } \\
\text { difference (I-J) }\end{array}$ & $\begin{array}{l}\text { Standard } \\
\text { error }\end{array}$ & $P$ value & $\begin{array}{c}95 \% \text { Confidence } \\
\text { interval }\end{array}$ \\
\hline \multirow[t]{6}{*}{ Clotting time } & GPVA & $\mathrm{AHA}$ & $340.9^{*}$ & 0.205 & $<0.0005$ & 340.45 to 341.42 \\
\hline & & Control & $353.2^{\star}$ & 0.205 & $<0.0005$ & 352.81 to 353.78 \\
\hline & $\mathrm{AHA}$ & GPVA & $-340.9^{\star}$ & 0.205 & $<0.0005$ & -341.42 to -340.45 \\
\hline & & Control & $12.35^{\star}$ & 0.205 & $<0.0005$ & 11.87 to 12.85 \\
\hline & Control & GPVA & $-353.2^{*}$ & 0.205 & $<0.0005$ & -353.78 to -352.81 \\
\hline & & $\mathrm{AHA}$ & $-12.35^{\star}$ & 0.205 & $<0.0005$ & -12.85 to -11.87 \\
\hline \multirow[t]{6}{*}{ Fibrinogen level } & GPVA & $\mathrm{AHA}$ & $1.264^{*}$ & 0.174 & $<0.0005$ & 0.8503 to 1.6793 \\
\hline & & Control & $2.570^{\star}$ & 0.174 & $<0.0005$ & 2.1562 to 2.9852 \\
\hline & $\mathrm{AHA}$ & GPVA & $-1.264^{*}$ & 0.174 & $<0.0005$ & -1.6793 to -0.8503 \\
\hline & & Control & $1.305^{\star}$ & 0.148 & $<0.0005$ & 0.9517 to 1.6601 \\
\hline & Control & GPVA & $-2.570^{\star}$ & 0.174 & $<0.0005$ & -2.9852 to -2.1562 \\
\hline & & $\mathrm{AHA}$ & $-1.305^{\star}$ & 0.148 & $<0.0005$ & -1.6601 to -0.9517 \\
\hline
\end{tabular}

Abbreviations: $\mathrm{AHA}=$ Agkistrodon halys antivenom; GPVA = green pit viper antivenom

* The mean difference is significant at the 0.05 level 
coagulopathy. The species $A$ halys ranges from Russia to northern and central China. Its venom contains metalloproteinase, haemotoxins, and neurotoxins. ${ }^{13}$ A bite may produce local swelling, ecchymosis, and neurotoxicity, mostly in the form of ptosis, blurred vision, and diplopia. ${ }^{14}$

Despite the differences in zoology and toxicology between $T$ albolabris and $A$ halys, AHA has been shown to be more effective than GPVA on a volume basis in the reduction of mouse mortality arising from $T$ albolabris envenoming. In an in-vivo study, the intraperitoneal lethal dose $50\left(\mathrm{LD}_{50}\right)$ of $T$ albolabris (called Cryptelytrops albolabris in the study but $T$ albolabris is the latest name for the same species) was elevated from $0.14 \mu \mathrm{L}$ to $0.36 \mu \mathrm{L}$ and $0.52 \mu \mathrm{L}$ by GPVA and AHA, respectively; and the effective dose 50 was $32.02 \mu \mathrm{L}$ for GPVA and $6.98 \mu \mathrm{L}$ for AHA. ${ }^{8}$ Nonetheless these favourable results for AHA may not be applicable to humans for several reasons. Firstly, haemotoxicity rather than death is the primary concern in T albolabris bite. In the above paper, the authors also pointed out the need for further study of clinically relevant toxicities other than mortality. ${ }^{8}$ Second, studies in animals revealed that the mortality and haemotoxicity outcomes might not correlate with each other. Of the six Trimeresurus species including $T$ albolabris in Thailand, there was an inconsistent ratio between the $\mathrm{LD}_{50}$ and minimum haemorrhagic dose (MHD). ${ }^{15}$ An animal study on $T$ albolabris venom revealed that GPVA antivenom could neutralise a greater $\mathrm{LD}_{50}$ than $\mathrm{Habu}$ antivenom (200 by GPVA, 106 by Habu) and likewise a greater MHD (2000 by GPVA, 750 by Habu). ${ }^{16}$ Sánchez et $\mathrm{al}^{17}$ tested the efficacy of two antivenoms against $\mathrm{LD}_{50}$ and MHD of different snakes of North America. Within a single species, the relative superiority of one antivenom might apply to only one outcome, ie $\mathrm{LD}_{50}$ or MHD, but not both.

We evaluated the antivenoms on a volume basis in order to simulate the way in which a patient is treated. Evaluation based on molecular weight and contents of proteins, all immunoglobulins or specific immunoglobulins towards venom antigens are alternative methods. Given that GPVA and AHA are supplied in powder form without a dosage-based weight and dissolved in liquid for administration, a volume-based result is deemed more practical for clinical dosing and drug reconstitution.

In human snakebite victims, venom is mostly deposited subcutaneously, not intravascularly. We employed a dose of venom assumed to be higher than that achievable in the plasma of most human snakebite victims for two reasons. First, the primary aim of this study was to compare the relative potency of two antivenoms, therefore a single dose of venom in both antivenom groups was more important than the dose quantity itself. Second, there were inadequate data on the usual venom concentrations, particularly the concentrations associated with coagulopathy, in the circulation of humans bitten by T albolabris.

In 1981, Visudhiphan et $\mathrm{al}^{18}$ reported the effect of GPVA on clotting time and fibrinogen level in human plasma exposed to green pit viper (Trimeresurus) venom. The venom promoted clotting and depleted fibrinogen level in a dosedependent fashion. After incubation of the venom with plasma at a concentration of $5 \mu \mathrm{g} / \mathrm{mL}$ (the same concentration employed in our study), clotting time was 12 minutes at 1 hour and a drop in fibrinogen level from that of normal plasma control occurred at 45 minutes. At the same venom plasma concentration $(5 \mu \mathrm{g} / \mathrm{mL})$ and for the same incubation time, GPVA added to plasma in a volume ratio of 1:5 prolonged the clotting time to more than 3 times that of the saline control, and there was failure to correct the hypofibrinogenaemia in 1:20 samples. ${ }^{18}$ In contrast, we observed a marked antidotal response to GPVA. It is possible that the purity of the antivenom has improved over the intervening years.

There are limitations to our study. First, in addition to its procoagulant and fibrinolytic effects on the coagulation pathway, $T$ albolabris venom also affects platelets. Of the patients in a local case series, thrombocytopenia was detected in $29 \%$ of cases, not necessarily associated with prolongation of PT or aPTT. ${ }^{4}$ Future study may consider checking for any thrombocytopenia. Second, laboratory and clinical outcomes may be disparate. In contrast with its inferior clinical performance, the Behringwerke antivenom has been proven to be more effective than the Pasteur antivenom in promoting mouse survival. ${ }^{19}$ Third, potential inconsistencies in the composition of antivenoms in various batches and venoms derived from individual snakes may affect the applicability of the results in another setting. Nevertheless given the in-vitro benefits of GPVA in antagonising coagulopathy in our study, future trials, particularly in-vivo clinical trials, should be conducted to determine its effect on other clotting parameters and the required dosage. Furthermore, fibrin formation (precipitation) and clotting time were recorded by a single observer who was not blinded to the treatment. This could have introduced information bias.

\section{Conclusions}

We conducted in-vitro clotting and fibrinogen assays on human plasma to assess the relative therapeutic effects of GPVA and AHA on the haemotoxicity produced by $T$ albolabris envenomation. The results indicated a higher potency of GPVA than AHA in neutralisation of the thrombin-like and hypofibrinogenaemic activities of $T$ albolabris venom. 


\section{Acknowledgements}

The authors would like to thank Jeanie Sum-yin Mak, Lucy Man-chi Lai, Shuk-han Tang, and Shuk-ching Fan from the Department of Pathology of Tuen Mun Hospital for their technical support.

\section{Declaration}

All authors have disclosed no conflicts of interest.

\section{References}

1. Ng WS, Cheung WL. Snake bites in Hong Kong (T. albolabris and other species): clinical features and management. Hong Kong J Emerg Med 1998;5:71-6.

2. Pongpit J, Limpawittayakul P, Juntiang J, Akkawat B, Rojnuckarin P. The role of prothrombin time (PT) in evaluating green pit viper (Cryptelytrops sp) bitten patients. Trans R Soc Trop Med Hyg 2012;106:415-8.

3. Cockram CS, Chan JC, Chow KY. Bites by the white-lipped pit viper (Trimeresurus albolabris) and other species in Hong Kong. A survey of 4 years' experience at the Prince of Wales Hospital. J Trop Med Hyg 1990;93:79-86.

4. Chan JC, Kwok MM, Cockram CS, Prematilleke MN, Tomlinson B, Critchley JA. Blood coagulation abnormalities associated with envenoming by Trimeresurus albolabris in Hong Kong. Singapore Med J 1993;34:145-7.

5. Rojnuckarin P, Intragumtornchai T, Sattapiboon R, et al. The effects of green pit viper (Trimeresurus albolabris and Trimeresurus macrops) venom on the fibrinolytic system in human. Toxicon 1999;37:743-55.

6. Management of snakebite. Accident and emergency clinical guidelines number 9. Hong Kong: Central Coordinating Committee of Accident and Emergency Services, Hospital Authority; 2008.

7. Yang JY, Hui H, Lee AC. Severe coagulopathy associated with white-lipped green pit viper bite. Hong Kong Med J 2007;13:392-5.

8. Fung HT, Yung WH, Crow P, et al. Green pit viper antivenom from Thailand and Agkistrodon halys antivenom from China compared in treating Cryptelytrops albolabris envenomation of mice. Hong Kong Med J 2012;18:40-5.

9. Management guidelines for snakebite. Hong Kong: Accident and Emergency Department, New Territories West Cluster, Hospital Authority; 2014.

10. Thomas S. LD50 scores for various snakes. Available from: http://www.seanthomas.net/oldsite/ld50tot.html. Accessed 17 Nov 2014.

11. Soogarun S, Sangvanich P, Chowbumroongkait M, et al. Analysis of green pit viper (Trimeresurus albolabris) venom protein by LC/MS-MS. J Biochem Mol Toxicol 2008;22:225-9.

12. Asazuma N, Marshall SJ, Berlanga O, et al. The snake venom toxin alboaggregin-A activates glycoprotein VI. Blood 2001;97:3989-91.

13. Li S, Wang J, Zhang X, et al. Proteomic characterization of two snake venoms: Naja naja atra and Agkistrodon halys. Biochem J 2004;384:119-27.

14. Agkistrodon halys bite treated with specific antivenin. Observation of 530 cases. Chin Med J (Engl) 1976;2:59-62.

15. Chanhome L, Khow O, Omori-Satoh T, Sitprija V. Capacity of Thai green pit viper antivenom to neutralize the venoms of Thai Trimeresurus snakes and comparison of biological activities of these venoms. J Nat Toxins 2002;11:251-9.

16. Pakmanee N, Khow O, Wongtongkam N, Omori-Satoh T, Sitprija V. Efficacy and cross reactivity of Thai green pit viper antivenom among venoms of Trimeresurus species in Thailand and Japan. J Nat Toxins 1998;7:173-83.

17. Sánchez EE, Galán JA, Perez JC, Rodríguez-Acosta A, Chase PB, Pérez JC. The efficacy of two antivenoms against the venom of North American snakes. Toxicon 2003;41:357-65.

18. Visudhiphan S, Dumavibhat B, Trishnananda M. Prolonged defibrination syndrome after green pit viper bite with persisting venom activity in patient's blood. Am J Clin Pathol 1981;75:65-9.

19. Warrell DA, Warrell MJ, Edgar W, Prentice CR, Mathison J, Mathison J. Comparison of Pasteur and Behringwerke antivenoms in envenoming by the carpet viper (Echis carinatus). Br Med J 1980;280:607-9. 